\title{
Journal of Religion and Health \\ Chaplains on the Medical Team: A Qualitative Analysis of an Interprofessional Curriculum for Internal Medicine Residents and Chaplain Interns \\ --Manuscript Draft--
}

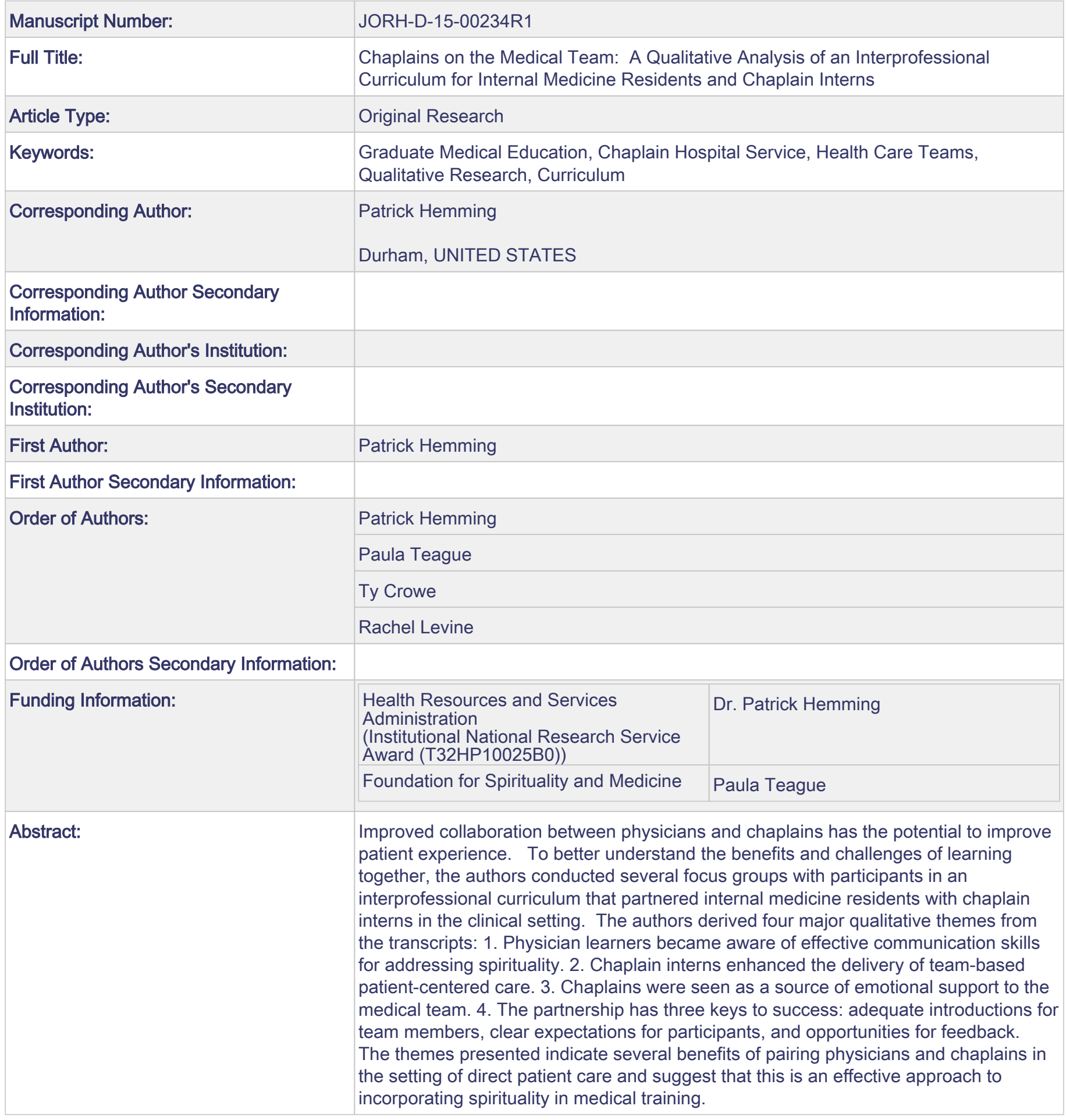


Curtis Hart, MDiv

Editor-in-Chief

Journal of Religion and Health

Dear Mr. Hart,

Accompanying this letter is our revision of "Chaplains on the Medical Team: A Qualitative Analysis of an Interprofessional Curriculum for Internal Medicine Residents and Chaplain Interns" JORH-D-15-00234. We thank you and the reviewers for the continued thoughtful consideration of our manuscript. We have revised the paper in response to the reviewers' comments and we hope that it will now be acceptable for publication in the Journal of Religion and Health. For ease of your review, we have noted each reviewer comment in italics. Our responses are provided directly below each comment.

Reviewer \#1: Very important work. Manuscript reads well. the only revision that I would like to see is if the author would provide more about Theme 4 in the text of the manuscript rather than directing me to a Table. As a reader, I only want to go to a table if I want more details. Maybe in the text, an exemplar quote would suffice.

We thank the reviewer for the suggestion in better presenting our findings. Accordingly, we have removed Table 3 from the manuscript, and have instead added a section with an introduction to each component of Theme 4 and representative quotes. To better organized findings for the readers, we have added bold headings for each theme, and underlined headings for the sub-themes in Theme 4. We have also corrected several small errors in the text, and improved the wording of some of the text.

Thank you for this very important work. Hopefully, this will model for other MD's how to address spiritual needs of patients. Interestingly, the curriculum was of benefit to the healthcare provider as well. I see lots of benefits for patient outcomes from this work.

We appreciate the positive regard of this reviewer, and certainly hope that our work will inspire other innovations in the fields of health care education.

In conclusion, we greatly appreciated the opportunity to revise our manuscript. We believe it has been improved by the review process and will make a significant contribution to the fields of medicine and pastoral care.

Sincerely,

Patrick Hemming, MD MPH 



\section{Chaplains on the Medical Team: A Qualitative Analysis of an Interprofessional Curriculum for Internal Medicine Residents and Chaplain Interns}

Authors:

Patrick Hemming, MD, MPH, Paula J. Teague, D.Min, MBA, Thomas (Ty) Crowe, M.Div, Rachel Levine, MD, MPH

Dr. Hemming is a Medical Instructor, Division of General Internal Medicine at the Duke University School of Medicine, Durham, NC

Dr. Teague is the Senior Director of the Department of Spiritual Care and Chaplaincy, Johns Hopkins Health System, Baltimore, MD

Mr. Crowe is Director of the Department of Spiritual Care and Chaplaincy, Johns Hopkins Hospital, Baltimore, MD

Dr. Levine is Associate Professor, Division of General Internal Medicine, Johns Hopkins School of Medicine, Baltimore, MD

Corresponding Author:

Patrick Hemming, MD MPH, Medical Instructor, Division of General Internal Medicine, Duke University School of Medicine. Dr. Hemming recently finished a general internal medicine fellowship at Johns Hopkins University, and teaches and supervises residents and practicing general internal medicine at Duke University.

4220 N Roxboro Rd, Durham, NC 27704. Phone: 919-471-8344. Fax: 919-477-5435

E-mail: Patrick.hemming@duke.edu

Abbreviations: JHBMC (Johns Hopkins Bayview Medical Center), CPE (Clinical Pastoral

Education), PH (Patrick Hemming), PT (Paula Teague)

Support: This project was funded by a grant from the Foundation for Spirituality and Medicine, Baldwin, MD 
Dr. Hemming was supported while completing this project by a Health Resources Services Administration Institutional National Research Service Award (T32HP10025BO) 


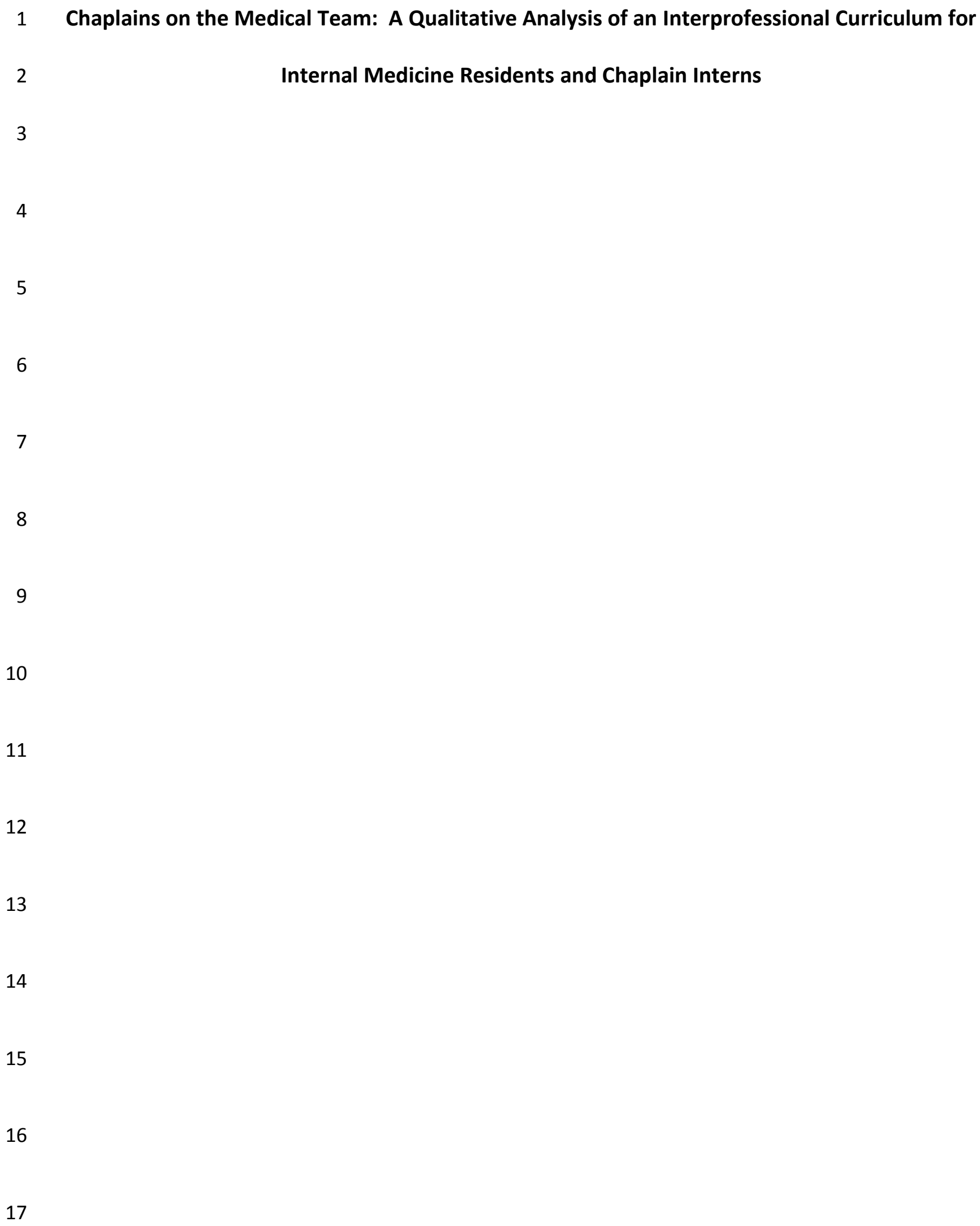


1

2 Improved collaboration between physicians and chaplains has the potential to improve patient

3 experiences. To better understand the benefits and challenges of learning together, the

4 authors conducted several focus groups with participants in an interprofessional curriculum

5 that partnered internal medicine residents with chaplain interns in the clinical setting. The

6 authors derived four major qualitative themes from the transcripts: 1 . Physician learners

7 became aware of effective communication skills for addressing spirituality. 2. Chaplain interns

8 enhanced the delivery of team-based patient-centered care. 3. Chaplains were seen as a source

9 of emotional support to the medical team. 4. The partnership has three keys to success:

10 adequate introductions for team members, clear expectations for participants, and

11 opportunities for feedback. The themes presented indicate several benefits of pairing

12 physicians and chaplains in the setting of direct patient care and suggest that this is an effective 13 approach to incorporating spirituality in medical training.

\section{Key words:}

15 Graduate Medical Education, Chaplain Hospital Service, Health Care Teams, Qualitative 16 Research, Curriculum 


\section{Introduction:}

2 Many patients see spirituality as important in their lives, and state a need to feel connected in

3 their medical care to their faith or spiritual beliefs (MacLean et al., 2003; Pearce, Coan,

4 Herndon, Koenig, \& Abernethy, 2012). Spirituality has been defined as "the aspect of humanity

5 that refers to the way individuals seek and express meaning and purpose and the way they

6 experience their connectedness to the moment, to self, to others, to nature, and to the

7 significant or sacred (Puchalski et al., 2009)." As members of patients' inpatient support

8 structure (Piderman et al., 2010), hospital chaplains specialize in addressing these patient needs

9 and can contribute significantly to patients' satisfaction with care (Clark, Drain, \& Malone, 10 2003; J. A. Williams, Meltzer, Arora, Chung, \& Curlin, 2011).

11 In current hospital practice, physicians and chaplains generally have limited understanding of 12 each other's expertise, and collaborate infrequently in patient care. Although others have 13 published interprofessional curricula pairing chaplains with nurses and social workers (Forrest \& 14 Derrick, 2010; Otis-Green et al., 2009), and some curricula report involvement of chaplains in 15 medical student teaching (Talley \& Magie, 2014), very little literature exists on interprofessional 16 education that pairs chaplain and physician learners (King \& Crisp, 2005).

17 With regard to collaborating in patient care, physicians and chaplains each have gaps in their 18 training. Among physicians, many report feeling inadequate to address patients' spiritual needs 19 (M. J. Balboni et al., 2014; Chibnall, Bennett, Videen, Duckro, \& Miller, 2004). Studies have 20 found that physicians express less positive attitudes toward addressing spirituality than other 21 members of the healthcare team (Phelps et al., 2012), although other studies generally show a 
1 receptiveness to chaplains (Fitchett, Rasinski, Cadge, \& Curlin, 2009). Chaplains may not be

2 accustomed to or be comfortable approaching physicians in connection with a patient's care.

3 The potential benefits of pairing physicians and chaplains include greater patient and provider

4 satisfaction, increased degrees of teamwork, improved spiritual care attitudes, and care that is

5 more patient-centered and value-based (Fulford, Peile, \& Carroll, 2012). A focus on spiritual

6 care has been associated with positive patient outcomes, such as quality of life (Vallurupalli et

7 al., 2012) and receipt of appropriate end-of-life care (T. A. Balboni et al., 2013). Teaching

8 spirituality in patient care might benefit from an interprofessional approach, especially one that

9 involves physicians and chaplains. Interprofessional education in health care has demonstrated 10 both educational and patient-level benefits in other settings (J. C. Campbell et al., 2001; Morey

11 et al., 2002; Reeves et al., 2010). Existing curricula aimed at teaching physicians about the 12 spiritual care of patients tend to target medical students, only occasionally involve chaplains, 13 and are not set in the context of direct patient care (N. Campbell, Stuck, \& Frinks, 2012; Fortin 14 A.H. \& Barnett, 2004; Galanter, Dermatis, Talbot, McMahon, \& Alexander, 2011). To address 15 these needs, we initiated an interprofessional educational partnership in 2011, pairing chaplain 16 interns and medical residents in the direct care of hospitalized patients. This paper reports on 17 the findings of a qualitative analysis of participants' experience with this curriculum.

\section{Methods}

\section{Study design:}

20 Using focus group discussions, we aimed to identify perceived benefits and challenges 21 experienced by participants in the curriculum. To do this, we conducted a qualitative analysis 
1 of transcripts from four different focus groups made up of participants from the first two years

2 of the curriculum at Johns Hopkins Bayview Medical Center (JHBMC) in Baltimore, MD. Focus

3 groups included internal medicine supervising attending physicians, chaplain interns and

4 internal medicine residents. A Johns Hopkins Institutional Review Board approved the study,

5 and we obtained informed consent from all participants.

7 Setting and participants:

8 In 2011, The Clinical Pastoral Education (CPE) program for chaplain training and the internal

9 medicine residency program at JHBMC began a rotation partnering chaplain interns with an 10 inpatient medicine teaching service. Chaplain interns at JHBMC are individuals currently or 11 previously enrolled in masters-level theology programs who are seeking a clinical application 12 for their skill (McClung, Grossoehme, \& Jacobson, 2006). Our CPE internship, similar to other 13 programs is six months in duration, and requires time spent working with patients on inpatient 14 services. For many chaplain interns in our program, this is their first experience working in a 15 hospital and many have come to chaplaincy from other careers. These interns also have a 16 variety of religious traditions.

17 The goals of the curriculum are to improve medical residents' ability to provide care that is 18 sensitive to patients' spiritual needs, and to better equip chaplain trainees to work with 19 physicians. Chaplain interns are paired with the medicine team to work together one day per 20 week for 4 consecutive weeks on the Aliki service. The Aliki service is a unique ward team with 21 a lower patient census where the chief aim is to ensure that residents know their patients as 
1 individuals (Ratanawongsa et al., 2009). Since morning bedside work-rounds are standard on

2 this service, we chose this as the setting for the partnership to facilitate opportunities for

3 chaplain and physician learners to observe and learn from one another. All internal medicine

4 residents rotate through this service at some time during their three years on rotations that are

52 to 4 weeks. At the time of the findings published here, almost all of the 57 residents had

6 rotated on this service with a chaplain intern. Each year, all four JHBMC chaplain interns had

7 experienced a rotation with the medical team, for a total of 12 participants. Nearly all of the 15

8 faculty physicians who regularly attend on this medical service had worked with a chaplain

9 intern on the service.

10 During the four week rotation, chaplain interns spend one day per week rounding with the

11 medical team. They are introduced to patients as a member of the team and participate in

12 morning rounds at the bedside. During the afternoon, they partner with the team in supporting

13 patient care by returning to see patients identified as having spiritual needs. Patients may

14 decline to have a return chaplain visit. Chaplain interns are expected to teach the medical team

15 briefly about their role as a chaplain and how to do an initial spiritual assessment. Chaplain

16 interns are provided opportunities to role model discussions about spirituality with patients

17 during bedside rounds.

18 Data collection:

19 We conducted six separate focus groups between December 2012 and May 2015; one with 20 attending physicians $(n=10)$, three with groups of chaplain interns $(n=4, n=3, n=3)$, and two with 21 medical residents ( $n=4, n=6)$. Focus group facilitators used the prompts developed by the 
1 curriculum development team to guide the discussion (Table 1). We intended for prompts to

2 be open-ended, exploratory and to elicit both positive and negative aspects of the partnership.

3 Based on prior anecdotal feedback, we hypothesized that participants would learn more about

4 communication skills and interprofessional work. We also anticipated that participants would

5 have challenges related to defining the role of a chaplain on the medical team.

6 Focus groups lasted from 30 minutes to one hour, and were audio-recorded. One physician

7 researcher $(\mathrm{PH})$ conducted focus groups with groups from three years of chaplain interns. The

8 first of these was done with four recent graduates of the internship, and the second on

9 participants' last day of internship. The same researcher conducted the focus group with 10 participating attending physicians at midpoint through the second year of the curriculum. Our

11 director of pastoral care (PT) conducted the interview with a convenience sample of four upper-

12 level medical residents at the end of the second year of the curriculum during a time regularly

13 set aside for ambulatory medicine didactics. A physician researcher $(\mathrm{PH})$ conducted another

14 focus group with a similar convenience sample of six upper-level residents in the third year of 15 the curriculum.

16 An administrative assistant transcribed the focus groups from the audiorecordings and an 17 author (PH) checked the transcript for errors. Two authors (PH and PT) separately coded each 18 of the transcripts for themes, using the editing analysis style in which researchers identify 19 segments of text that are meaningful to the context (Crabtree \& Miller, 1992). We compared 20 coding to examine for discrepancies and differences in interpretation. In the few instances 21 where differences in interpretation existed, we adjudicated them by discussion until we 22 reached agreement. We developed an outline of related themes across transcripts from these 
1 codes. We again checked this outline with the initial transcript. We contacted two

2 participating attending physicians, two internal medicine residents and one chaplain intern to

3 review the themes developed from their statements to confirm accuracy. Representative

4 quotes were agreed on by all authors.

\section{Results}

6 Table 2 presents the demographics of the focus group participants. Four major themes

7 emerged from the discussions in each of the focus groups.

8 Theme one: Both attending physicians and residents became aware of effective

9 communication skills for addressing spirituality

10 Physicians noted that they were introduced to new ways of approaching patient interactions

11 from observing chaplain interns speaking at the bedside with the patient on rounds. These new

12 techniques included active listening, observing, and using appropriate language for discussing

13 spirituality. Multiple residents described learning how effectively they could help patients by

14 simply being present and using silence. One resident described how she observed patients

15 differently:

16 "One thing that I learned is to be more observant of the patient's room. Some people have the

17 bible on the table or some scriptures for the morning and those provided an opening for the

18 chaplain interns to engage the patient in conversation. And I would never have noticed them

19 before."

20 One attending physician felt that watching chaplain interns model communication taught these 21 skills more effectively than other potential teaching methods: 
1 "I felt that that experience with the team was very educational and more than what we could

2 have learned in a didactic session - seeing someone at the bedside discussing spirituality."

3 A chaplain intern mentioned that after she had spoken with a patient in the presence of the

4 rest of the team, she witnessed residents using the same greeting and introduction with other

5 patients.

6 Theme two: Chaplain interns enhanced the delivery of team-based patient-centered care

7 Both attending physicians and residents appreciated the ability of chaplain interns to invite

8 patients to share their own experience, by asking about important aspects of their lives. When

9 chaplain interns shared these interactions with the medical team, everyone was better able to 10 know their patients personally. One resident stated:

11 "The chaplain can come back and summarize to the team the salient details: social issues,

12 family dynamics, personal suffering, and their understanding of how the patients' spirituality or 13 religiosity intertwines with what's going on medically."

14 Also, physicians perceived the chaplain interns as extremely helpful in addressing the care of 15 patients who were viewed as being more difficult to work with, as expressed by one attending 16 physician:

17 "An example was a very challenging patient, a young man who lacked any social support, had a 18 lot of pain and expressions of frustration. The chaplain intern helped the patient work through 19 some of them and helped the team work through some of them." 
1 One chaplain intern mentioned that at times she was able to refocus bedside discussion on

2 rounds from a biomedical focus back to the patient's psychosocial experience:

3 "If the patient would become agitated or anxious, my job is to try to bring calm, or peace or

$4 \quad$ understanding where there may not have been. The doctors were often sensitive as to when we

5 needed to intervene. "

6 Theme Three: Chaplains may be a source of emotional support to the medical team

7 Multiple physician participants noted instances when, in the event of a challenging patient

8 event (such as a death or the need to deliver bad news), the chaplain intern took the

9 opportunity to lead a brief reflection on the experience. Both attending and resident physicians

10 welcomed this approach. In one case, when a patient was transferred to the intensive care unit

11 and died unexpectedly, the chaplain intern was able to follow the patient and family through

12 these events. When she debriefed the team, it provided a sense of continuity and closure.

13 Regarding the experience, a resident said:

14 "We were able to sit together as a team to hear a little bit more about what had happened from

15 the chaplain's experience and had everyone else reflect on what their experience was with that

16 patient or other experiences with patients' deaths in our training."

17 For chaplain interns, they learned from these interactions that they could lend meaningful

18 support to their physician colleagues. One chaplain intern noted: 
1 "I realized that my presence was helpful to the team when we went to hospice to visit a patient;

2 to see how they depended on me then because it was so emotional for them. Before then I

3 really didn't know what my presence meant to them."

4 Medical residents saw chaplain interns as individuals who had expertise in handling some of the

5 negative emotions that arise during patient care. One resident stated:

6 "Chaplains actually have a lot of training on counter-transference and how to adjust to what

7 patients' actions make us feel, and some of that gets to the idea of how to become a whole

8 provider, and sort through some of the frustrations and anger and sadness that come from

9 dealing in the medical field."

10 Theme Four: This interprofessional partnership has three keys to success: adequate

11 introductions for team members, clear expectations, and opportunities for feedback

12 Adequate Introductions

13 Chaplain interns noted that their integration in the team often depended on whether

14 introductions occurred or not. In situations where no introduction was made, they perceived

15 themselves as very peripheral to the team.

16 "The team always changed, and introductions are really important to the chaplains to show that 17 you're important, or they're glad that you're here: Tell us a little bit about yourself."

18 Chaplain interns felt more integrated when physicians introduced the chaplains to patients as a 19 part of the team. Medical residents noted that they appreciated knowing a little bit more 20 about the CPE trainee, and that this fostered collaboration. 


\section{$1 \quad$ Clear Expectations}

2 Early in the project, we became aware of the need to clarify for chaplain interns what was

3 expected of them. The lack of clarity caused frustration at times for both physicians and CPE

4 trainees. Attending physicians, unused to incorporating a chaplain on the team found it difficult

5 to bring them into rounds. In other cases, CPE trainees were eager to participate and

6 contributed to rounds in ways that were seen as distracting or inappropriate by the attending.

7 It became apparent that each participant needed up-front expectations of how to interact

8 across professional disciplines in rounds.

9 One chaplain intern noted:

10 "I had some time with the attending alone the first time I went over. She explained to me what

11 they did and how they made their rounds. It's just helpful to get that. It's a matter of clarifying

12 what to expect."

13 One attending noted mismatched expectations with a chaplain intern:

14 "We just never got a good system down of how and when to have these conversations. We had

15 a lot of patients to see and I felt like that the (chaplain intern) didn't pick up on the cues when

16 we were in a hurry and would stop rounds and ask a lot of questions."

17 Opportunities for Feedback

18 Chaplain interns early in the curriculum noted a lack of feedback on their contributions: 
1 "You would just leave at the end of the day and think "I have no idea what any of them thought.

2 If there's no direct feedback, you don't have a way of finding out that you really haven't maybe

3 been doing what's appropriate."

\section{Discussion:}

5 This work describes a new pairing in the field of interprofessional education. Medical and

6 clinical pastoral education have developed in parallel, but without intersection for nearly a

7 century (Gregory, 2003). The first three themes presented suggest strong potential to jointly

8 advance training in core competencies of each profession.

9 Medical schools, and to a lesser degree, residencies are adding training on spirituality to the 10 formal curriculum (Fortin \& Barnett, 2004; King \& Crisp, 2005; H. G. Koenig, Hooten, Lindsay11 Calkins, \& Meador, 2010); however, these curricula do not generally use experiential learning in 12 the context of direct patient care. Experiences that are relevant to the learners and allow for 13 cycles of practice and reflection are highly effective in teaching skills and affecting behaviors 14 (Kolb, 1984). In our curriculum, the interprofessional team approach--where participants 15 observe one another and discuss their experiences-- allowed both sets of trainees to directly 16 apply new skills and knowledge.

17 Some medical educators have developed proposed spiritual care competencies for physicians' 18 training (Anandarajah \& Mitchell, 2007; Puchalski et al., 2009). In our curriculum, residents 19 participated in activities related to these competencies, such as taking a patient's spiritual 20 history, listening empathically and communicating a follow-up plan. Participants had the sense 
1 that through these activities they knew their patients better as individuals. By eliciting patient

2 values and preferences for care as a context for patients' disease, this biopsychosocial approach

3 fits textbook descriptions of patient-centered care (Smith, Fortin, Dwamena, \& Frankel, 2013;

4 Stewart, 2003). Our participants felt that they were able to learn directly from the patient.

5 Other published medical curricula have similarly sought to allow the patient to be the teacher

6 (Henriksen \& Ringsted, 2011; Towle \& Godolphin, 2013).

7 Additionally, resident and attending physicians reported learning by observing. Social Cognitive

8 Theory suggests that learners adopt attitudes and behaviors commonly through observational

9 learning (Bandura, 1989). Wright and Reed have also described role modeling as invaluable to 10 learners' development (Reed \& Wright, 2010). Chaplain interns were able to demonstrate to 11 medicine residents communication skills taught in Clinical Pastoral Education, such as non12 judgmental communication, active listening, and reflection on experience (ACPE standards and 13 manuals.2010). Chaplain interns then noticed medical residents using similar language with 14 patients following their shared interactions during rounds, suggesting that residents were using 15 practices they observed.

16 We did not initially envision that chaplain interns and medical teams would engage in mutual 17 emotional support. Without prompting, they took the opportunity to reflect on loss and grief in 18 a way that was therapeutic to members of the team. Residents described these experiences as 19 form of support group. Residents face significant distress in the course of their training and this 20 is linked to burnout, depression, at-risk drinking, suboptimal patient care, absenteeism, job 21 turnover and decreased satisfaction (Balch \& Shanafelt, 2010; McCray, Cronholm, Bogner, 
1 Gallo, \& Neill, 2008; C. M. Williams, Wilson, \& Olsen, 2005). Different health professions,

2 including chaplains, have approaches to coping with these stresses (Ekedahl \& Wengström,

3 2008) and this role of caring for the medical team has been proposed elsewhere (H. G. Koenig,

4 2014). Other literature suggests that providers benefit from the use of support groups to

5 prevent burnout (Le Blanc, Hox, Schaufeli, Taris, \& Peeters, 2007; Walter, Plaumann, \&

6 Krugmann, 2013). Focus group residents felt strongly that chaplain interns' interventions

7 provided coping strategies, and in some cases closure, to difficult experiences.

8 Theme four, which focuses on curricular logistics, presents several opportunities to improve

9 team-based learning. Prior work on interprofessional education has identified role definition as 10 important to the team's function (Suter et al., 2009). The Institute of Medicine (IOM) suggests

11 that teams require briefing and debriefing to learn (Institute of Medicine (US), 2011). Briefing, 12 or "when team members look ahead at the work to be performed," includes introducing team 13 members and naming expectations. Based on the focus group findings, we have ensured that a 14 chaplain supervisor is present to introduce chaplain interns to the team on their first day. To 15 better clarify expectations, we have modified chaplain interns' orientation to include 16 instruction on the structure of the medical team, and the function of rounds.

17 The IOM report also emphasizes debriefing in the medical team. Learners require debriefing in 18 the form of feedback on their performance with regard to previously identified expectations.

19 Educational literature suggests that feedback is most effective when it is specific, is based on 20 expectations, is constructive to the learner's performance, includes opportunities for dialogue, 21 and when future observations with targeted feedback occur (Archer, 2010; Van de Ridder, 
1 Stokking, McGaghie, \& ten Cate, 2008). To address the need for feedback, we developed a

2 structured feedback form that chaplain interns would use to elicit feedback from the attending

3 physician, which has since been used by participants.

4 This study has limitations. We were able to include nearly every chaplain intern and a majority

5 of participating attending physicians in a focus group; however, our sample of residents was

6 smaller. Accordingly, the themes and quotes may not be representative of all residents'

7 experience. Additionally, participants may have reported more positive experiences, given the

8 researchers' known involvement with the project. Our residency heavily emphasizes patient-

9 centered curricula, and our residents' attitudes may not be representative of internal medicine 10 residents generally. Also, our sample included a larger proportion of female participants than

11 might have been anticipated, potentially influencing our results. The chaplain interns, as shown

12 in Table 2 represent a variety of religious affiliations, but we did not ascertain the religious

13 affiliations of physician participants. Finally, as with any qualitative study, interpretations and

14 collection of data may be influenced by the biases of researchers.

15 This research raises the possibility of testable future research questions. A future survey of 16 curriculum participants may establish the prevalence of these themes, and the impact on 17 learners' skills and behaviors. We also have not yet collected direct patient perspectives, which 18 are essential to understanding the true impact of this educational model. Although patients 19 have reacted positively to the involvement of chaplain learners in their care, it is possible that 20 patients may be uncomfortable with having a chaplain as part of their medical team. 
1 In future evaluations, we intend to survey patients regarding their satisfaction with care and

2 perceptions of the team caring for them, as well as inquire directly about potential patient

3 objections to chaplain involvement and concerns about privacy and confidentiality.

4

\section{Conclusions:}

6 Our research suggests that medical residents, attending physicians and chaplain interns

7 working together in an interprofessional partnership can result in rich learning about patient-

8 centered communication, spiritual care and team-based care. Our participants' experiences

9 also demonstrate potential new strategies for addressing provider distress. In addition we also

10 found that, team-building exercises, such as group introductions, setting expectations and

11 feedback on performance are valuable in interprofessional team-based medical education. 
1

2 ACPE standards and manuals. (2010). (). Decatur, GA: Association for Clinical Pastoral

$3 \quad$ Education, Inc.

4 Anandarajah, G., \& Mitchell, M. (2007). A spirituality and medicine elective for senior medical

5 students: 4 years' experience, evaluation, and expansion to the family medicine residency.

$6 \quad$ Family Medicine, 39(5), 313-315.

7 Archer, J. C. (2010). State of the science in health professional education: Effective feedback.

$8 \quad$ Medical Education, 44(1), 101-108. doi:10.1111/j.1365-2923.2009.03546.x [doi]

9 Balboni, M. J., Sullivan, A., Enzinger, A. C., Epstein-Peterson, Z. D., Tseng, Y. D., Mitchell, C., . . . 10 Balboni, T. A. (2014). Nurse and physician barriers to spiritual care provision at the end of 11 life. Journal of Pain and Symptom Management, doi:S0885-3924(13)00669-6 [pii]

12 Balboni, T. A., Balboni, M., Enzinger, A. C., Gallivan, K., Paulk, M. E., Wright, A., ... Prigerson, H. 13 G. (2013). Provision of spiritual support to patients with advanced cancer by religious 14 communities and associations with medical care at the end of life. JAMA Internal Medicine, 15 173(12), 1109-1117. doi:10.1001/jamainternmed.2013.903;

$16 \quad$ 10.1001/jamainternmed.2013.903

17 Balch, C. M., \& Shanafelt, T. (2010). Combating stress and burnout in surgical practice: A review. 18 Advances in Surgery, 44, 29-47. 
1 Bandura, A. (1989). Human agency in social cognitive theory. American Psychologist, 44(9),

$2 \quad 1175$.

3 Campbell, J. C., Coben, J. H., McLoughlin, E., Dearwater, S., Nah, G., Glass, N., . . Durborow, N.

4 (2001). An evaluation of a system-change training model to improve emergency

5 department response to battered women. Academic Emergency Medicine : Official Journal

6 of the Society for Academic Emergency Medicine, 8(2), 131-138.

7 Campbell, N., Stuck, C., \& Frinks, L. (2012). Spirituality training in residency: Changing the 8 culture of a program. Academic Psychiatry, 36(1), 56-59.

9 Chibnall, J. T., Bennett, M. L., Videen, S. D., Duckro, P. N., \& Miller, D. K. (2004). Identifying 10 barriers to psychosocial spiritual care at the end of life: A physician group study. American 11 Journal of Hospice and Palliative Medicine, 21(6), 419-426.

12 Clark, P. A., Drain, M., \& Malone, M. P. (2003). Addressing patients' emotional and spiritual 13 needs. Joint Commission Journal on Quality and Safety, 29(12), 659-670.

14 Crabtree, B. F., \& Miller, W. L. (1992). Doing qualitative research. Newbury Park, Calif.: Sage 15 Publications.

16 Ekedahl, M., \& Wengström, Y. (2008). Coping processes in a multidisciplinary healthcare team: 17 A comparison of nurses in cancer care and hospital chaplains. European Journal of Cancer 18 Care, 17(1), 42-48. doi:10.1111/j.1365-2354.2007.00801.x 
1 Fitchett, G., Rasinski, K., Cadge, W., \& Curlin, F. A. (2009). Physicians' experience and satisfaction with chaplains: A national survey. Archives of Internal Medicine, 169(19), 18081810. doi:10.1001/archinternmed.2009.308 [doi]

Forrest, C., \& Derrick, C. (2010). Interdisciplinary education in end-of-life care: Creating new opportunities for social work, nursing, and clinical pastoral education students. Journal of Social Work in End-of-Life \& Palliative Care, 6(1-2), 91-116. doi:10.1080/15524256.2010.489224 [doi]

8 Fortin A.H., V., \& Barnett, K. G. (2004). STUDENTJAMA. medical school curricula in spirituality

9 and medicine. JAMA : The Journal of the American Medical Association, 291(23), 2883.

10 doi:10.1001/jama.291.23.2883

11 Fortin, A. H., VI, \& Barnett, K. G. (2004). Medical school curricula in spirituality and medicine. Journal of the American Medical Association, 291(23), 2883.

13 Fulford, K., Peile, E., \& Carroll, H. (2012). Essential values-based practice: Clinical stories linking $14 \quad$ science with people Cambridge University Press.

15 Galanter, M., Dermatis, H., Talbot, N., McMahon, C., \& Alexander, M. J. (2011). Introducing spirituality into psychiatric care. Journal of Religion and Health, 50(1), 81-91.

17 Gregory, S. R. (2003). Growth at the edges of medical education: Spirituality in american 18 medical education. The Pharos of Alpha Omega Alpha-Honor Medical Society.Alpha Omega 19 Alpha, 66(2), 14-19. 
1 Henriksen, A., \& Ringsted, C. (2011). Learning from patients: Students' perceptions of patient-

2 instructors. Medical Education, 45(9), 913-919. doi:10.1111/j.1365-2923.2011.04041.x

3 Institute of Medicine (US). (2011). doi:NBK91496 [bookaccession]

4 King, D. E., \& Crisp, J. (2005). Spirituality and health care education in family medicine residency 5 programs. Family Medicine, 37(6), 399-403.

6 Koenig, H. G. (2014). The spiritual care team: Enabling the practice of whole person medicine. $7 \quad$ Religions, 5(4), 1161-1174.

8 Koenig, H. G., Hooten, E. G., Lindsay-Calkins, E., \& Meador, K. G. (2010). Spirituality in medical 9 school curricula: Findings from a national survey. International Journal of Psychiatry in $10 \quad$ Medicine, 40(4), 391-398.

11 Kolb, D. A. (1984). Experiential learning: Experience as the source of learning and development 12 Prentice-Hall Englewood Cliffs, NJ.

13 Le Blanc, P. M., Hox, J. J., Schaufeli, W. B., Taris, T. W., \& Peeters, M. C. (2007). Take care! the 14 evaluation of a team-based burnout intervention program for oncology care providers. $15 \quad$ Journal of Applied Psychology, 92(1), 213.

16 MacLean, C. D., Susi, B., Phifer, N., Schultz, L., Bynum, D., Franco, M., . . Cykert, S. (2003).

17 Patient preference for physician discussion and practice of spirituality. Journal of General 18 Internal Medicine, 18(1), 38-43. 
1 McClung, E., Grossoehme, D. H., \& Jacobson, A. F. (2006). Collaborating with chaplains to meet spiritual needs. Medsurg Nursing : Official Journal of the Academy of Medical-Surgical Nurses, 15(3), 147-156.

McCray, L. W., Cronholm, P. F., Bogner, H. R., Gallo, J. J., \& Neill, R. A. (2008). Resident physician burnout: Is there hope? Family Medicine, 40(9), 626-632.

Morey, J. C., Simon, R., Jay, G. D., Wears, R. L., Salisbury, M., Dukes, K. A., \& Berns, S. D. (2002). Error reduction and performance improvement in the emergency department through formal teamwork training: Evaluation results of the MedTeams project. Health Services Research, 37(6), 1553-1581.

Otis-Green, S., Ferrell, B., Spolum, M., Uman, G., Mullan, P., Baird, R. P., \& Grant, M. (2009). An overview of the ACE project-advocating for clinical excellence: Transdisciplinary palliative care education. Journal of Cancer Education, 24(2), 120-126.

Pearce, M. J., Coan, A. D., Herndon, J. E.,2nd, Koenig, H. G., \& Abernethy, A. P. (2012). Unmet spiritual care needs impact emotional and spiritual well-being in advanced cancer patients. Supportive Care in Cancer : Official Journal of the Multinational Association of Supportive Care in Cancer, 20(10), 2269-2276. doi:10.1007/s00520-011-1335-1; 10.1007/s00520-011$1335-1$

Phelps, A. C., Lauderdale, K. E., Alcorn, S., Dillinger, J., Balboni, M. T., Van Wert, M., ... Balboni, T. A. (2012). Addressing spirituality within the care of patients at the end of life: Perspectives of patients with advanced cancer, oncologists, and oncology nurses. Journal 
of Clinical Oncology : Official Journal of the American Society of Clinical Oncology, 30(20), 2538-2544. doi:10.1200/JCO.2011.40.3766; 10.1200/JCO.2011.40.3766

Piderman, K. M., Marek, D. V., Jenkins, S. M., Johnson, M. E., Buryska, J. F., Shanafelt, T. D., . . Mueller, P. S. (2010). Predicting patients' expectations of hospital chaplains: A multisite survey. [Not medical educationTy] Mayo Clinic Proceedings, 85(11), 1002-1010.

Puchalski, C., Ferrell, B., Virani, R., Otis-Green, S., Baird, P., Bull, J., . . Sulmasy, D. (2009). Improving the quality of spiritual care as a dimension of palliative care: The report of the consensus conference. Journal of Palliative Medicine, 12(10), 885-904.

doi:10.1089/jpm.2009.0142; 10.1089/jpm.2009.0142

Ratanawongsa, N., Rand, C. S., Magill, C. F., Hayashi, J., Brandt, L., Christmas, C., ... Ziegelstein, R. C. (2009). Teaching residents to know their patients as individuals. the aliki initiative at johns hopkins bayview medical center. The Pharos of Alpha Omega Alpha-Honor Medical Society.Alpha Omega Alpha, 72(3), 4-11.

Reed, D. A., \& Wright, S. M. (2010). Role models in medicine. In H. J. Humphrey (Ed.), Mentoring in academic medicine (pp. 67-87) ACP Press.

Reeves, S., Zwarenstein, M., Goldman, J., Barr, H., Freeth, D., Koppel, I., \& Hammick, M. (2010). The effectiveness of interprofessional education: Key findings from a new systematic review. Journal of Interprofessional Care, 24(3), 230-241. doi:10.3109/13561820903163405 [doi] 
1 Smith, R. C., Fortin, A. H., Dwamena, F., \& Frankel, R. M. (2013). An evidence-based patient-

2

3 centered method makes the biopsychosocial model scientific. Patient Education and Counseling, 91(3), 265-270.

Stewart, M. (2003). Patient-centered medicine: Transforming the clinical method Radcliffe Publishing.

Suter, E., Arndt, J., Arthur, N., Parboosingh, J., Taylor, E., \& Deutschlander, S. (2009). Role understanding and effective communication as core competencies for collaborative practice. Journal of Interprofessional Care, 23(1), 41-51. doi:10.1080/13561820802338579 [doi]

Talley, J. A., \& Magie, R. (2014). The integration of the "spirituality in medicine" curriculum into the osteopathic communication curriculum at kansas city university of medicine and biosciences. Academic Medicine : Journal of the Association of American Medical Colleges, 89(1), 43-47. doi:10.1097/ACM.0000000000000078 [doi]

Towle, A., \& Godolphin, W. (2013). Patients as educators: Interprofessional learning for patientcentred care. Med Teach, 35(3), 219-225. doi:10.3109/0142159X.2012.737966

Vallurupalli, M., Lauderdale, K., Balboni, M. J., Phelps, A. C., Block, S. D., Ng, A. K., . . Balboni, T. A. (2012). The role of spirituality and religious coping in the quality of life of patients with advanced cancer receiving palliative radiation therapy. The Journal of Supportive Oncology, 10(2), 81-87. doi:10.1016/j.suponc.2011.09.003; 10.1016/j.suponc.2011.09.003 
1 Van de Ridder, J. M. M., Stokking, K. M., McGaghie, W. C., \& ten Cate, O. T. J. (2008). What is 2 feedback in clinical education? Medical Education, 42(2), 189-197.

3 Walter, U., Plaumann, M., \& Krugmann, C. (2013). Burnout intervention. In S. BÃ ̧hrer-Kohler

$4 \quad$ (Ed.), (pp. 223-246) Springer US. doi:10.1007/978-1-4614-4391-9_14

5 Williams, C. M., Wilson, C. C., \& Olsen, C. H. (2005). Dying, death, and medical education:

$6 \quad$ Student voices. Journal of Palliative Medicine, 8(2), 372-381.

7 Williams, J. A., Meltzer, D., Arora, V., Chung, G., \& Curlin, F. A. (2011). Attention to inpatients'

8 religious and spiritual concerns: Predictors and association with patient satisfaction.

9 Journal of General Internal Medicine, 26(11), 1265-1271. doi:10.1007/s11606-011-1781-y; $10 \quad 10.1007 / \mathrm{s} 11606-011-1781-y$ 


\section{Table 1: Focus Group Prompts}

During your experience working on a medical team that included chaplains,

1. What did you learn?

2. How did you change?

3. What was the value of this experience?

4. What could have been improved? 
Table 2: Demographics of Focus Group Members

\begin{tabular}{|l|l|l|}
\hline Attending physicians (n=10) & & \\
\hline Race: & Underrepresented minority & $0 \%$ \\
\hline Gender: & Female & $7(70 \%)$ \\
\hline Rank: & Professor & $2(20 \%)$ \\
\hline & Associate Professor & $3(30 \%)$ \\
\hline & Assistant Professor & $5(50 \%)$ \\
\hline Subspecialty: & Geriatrics & $5(50 \%)$ \\
\hline & General Internal Medicine & $3(30 \%)$ \\
\hline & Hospitalist & $2(20 \%)$ \\
\hline Chaplain Interns (n=10) & & \\
\hline Race: & & $4(40 \%)$ \\
\hline Gender: & Under-represented minority & $4(60 \%)$ \\
\hline Faith background: & Female & $7(70 \%)$ \\
\hline & Protestant & $2(29 \%)$ \\
\hline & Catholic & $1(14 \%)$ \\
\hline Internal Medicine Residents (n=10) & Jewish & \\
\hline Race: & & $\mathbf{3}$ \\
\hline Gender: & Under-represented minority & $1(10 \%)$ \\
\hline Residency Year: & Female & $6(60 \%)$ \\
\hline & PGY2 & $7(70 \%)$ \\
\hline & PGY3 & $3(30 \%)$ \\
\hline
\end{tabular}

